\title{
A Study on Patients' Perception of Dental Visits during the COVID-19 Pandemic
}

\author{
Seon Kyoung Lee ${ }^{1}$, Su Bin Kwon ${ }^{1}$, Hee Yeon Kim ${ }^{1}$, Kyoung Eun Oh${ }^{1}$, Young Eun Lee ${ }^{1}$ \\ ${ }^{1}$ Department of Dental Hygiene, Daegu Health College, Daegu, Republic of Korea
}

\begin{abstract}
Objectives: After the COVID-19 pandemic, the Korea Institute for Health and Social Affairs surveyed the medical service experience of 6,000 households nationwide from July to October last year and found that $19.3 \%$ of patients who used dental hospitals and clinics complained about infection anxiety. Therefore, this study tried to find a way to prevent the anxiety of coronavirus-19 infection that can be implemented in dentistry in the future by examining how patients' perception of dental visits has changed due to the COVID-19 pandemic.

Methods: This study conducted an online survey on May 2021, targeting 110 patients visiting dentists located in Daegu and Gyeongbuk. A structured self-administered questionnaire about general matters, dental visits, changes in dental visits due to the COVID-19, awareness and anxiety, future dental visits, the level of effort to prevent infection, other wishes was used for the survey.

Results: Most of the subjects of this study were familiar with the pathogen, infection route, and prevention methods of the COVID-19, and responded that they were experiencing daily life and mental discomfort due to the COVID-19 infection. However, many respondents said that they are not reluctant to visit the dentist at present, and they are willing to visit the dentist again if necessary in the future and that there is a need to visit the dentist.

Conclusions: Even though patients feel fear in their daily life due to the COVID-19, the study results showed that the perception of dental visits was positive. In addition, it is thought that the provision of customized treatment plans, such as adjusting the reservation time and treating patients in an individually separate space, according to the needs of patients who are reluctant to visit the dentist, can be a suggestion for an important preventive measure against the COVID-19.
\end{abstract}

Keywords: COVID-19, Dentistry, Visit recognition

Copyright (C) 2021. Korean Academy of Preventive Dentistry. All rights reserved.

This is an Open Access article distributed under the terms of the Creative Commons Attribution Non-Commercial License (http://creativecommons.org/licenses/ by-nc/4.0) which permits unrestricted non-commercial use, distribution, and reproduction in any medium, provided the original work is properly cited. 